\title{
Detection of cardiac biomarker proteins using a disposable based on a molecularly imprinted polymer grafted onto graphite
}

\author{
Felismina T.C. Moreira \& Sanjiv Sharma \& \\ Rosa A. F. Dutra \& João P. C. Noronha \& \\ Anthony E. G. Cass \& M. Goreti F. Sales
}

\begin{abstract}
A low-cost disposable was developed for rapid detection of the protein biomarker myoglobin (Myo) as a model analyte. A screen printed electrode was modified with a molecularly imprinted material grafted on a graphite support and incorporated in a matrix composed of poly(vinyl chloride) and the plasticizer o-nitrophenyloctyl ether. The proteinimprinted material (PIM) was produced by growing a reticulated polymer around a protein template. This is followed by radical polymerization of 4-styrenesulfonic acid, 2aminoethyl methacrylate hydrochloride, and ethylene glycol dimethacrylate. The polymeric layer was then covalently bound to the graphitic support, and Myo was added during the imprinting stage to act as a template. Non-imprinted control materials (CM) were also prepared by omitting the Myo template. Morphological and structural analysis of PIM and CM by FTIR, Raman, and SEM/EDC microscopies confirmed the modification of the graphite support. The analytical
\end{abstract}

performance of the SPE was assessed by square wave voltammetry. The average limit of detection is $0.79 \mu \mathrm{g}$ of Myo per $\mathrm{mL}$, and the slope is $-0.193 \pm 0.006 \mu \mathrm{A}$ per decade. The SPE$\mathrm{CM}$ cannot detect such low levels of Myo but gives a linear response at above $7.2 \mu \mathrm{g} \cdot \mathrm{mL}^{-1}$, with a slope of $-0.719 \pm$ $0.02 \mu \mathrm{A}$ per decade. Interference studies with hemoglobin, bovine serum albumin, creatinine, and sodium chloride demonstrated good selectivity for Myo. The method was successfully applied to the determination of Myo urine and is conceived to be a promising tool for screening Myo in point-ofcare patients with ischemia.

\section{Keywords}

Protein imprinting $\cdot$ Screen-printed electrodes $\cdot$ Cardiac biomarker · Myoglobin · Biosensor · Potentiometry

Introduction

Acute coronary syndrome (ACS) is a spectrum of acute myocardial ischemias ranging from unstable angina to acute myocardial infarction (AMI) [1, 2]. Patients suffering from AMI require a quick diagnosis from emergency medical assistance. The symptoms of chest pain, pressure, shortness of breath, and/or nausea are common to acute myocardial ischemia conditions [3]. The myocytes lose their membrane integrity in response to ischemia thereby releasing molecules into the peripheral circulation known as cardiac biomarkers. Screening cardiac biomarkers may be of great significance for a more accurate and quick diagnosis [4]. Myoglobin (Myo), cardiac troponin $\mathrm{T}(\mathrm{TnT})$, troponin $\mathrm{I}(\mathrm{TnI})$, and creatinine kinase $\mathrm{MB}$ (CK-MB) are the most relevant cardiac biomarkers for this purpose [5].

Serum Myo is a nonspecific biomarker that appears in the peripheral circulation as early as $1-2 \mathrm{~h}$ after cardiac damage. It precedes the elevation of TnT and CK-MB. Although Myo 
levels should not be used as the sole biomarker for the diagnosis of ACS, a normal Myo concentration within $2 \mathrm{~h}$ after presentation may exclude AMI [4, 6]. Myo cut-off levels range from 100 to $200 \mathrm{ng} \cdot \mathrm{mL}^{-1}[7,8]$, reaching levels of 420-2000 $\mathrm{ng} \cdot \mathrm{mL}^{-1}$ in serum [9] and $450 \mathrm{ng} \cdot \mathrm{mL}^{-1}$ in the urine [10]. Screening Myo in an emergency context is therefore important, and a suitable point-of-care (POC) assay would result in a reduced time to diagnosis and treatment [11].

Several methods have been described for Myo detection in physiological fluids. Some authors have developed immunoassay methods with fluorescence detection of high sensitivity [12-14]. Other immunoassay formats include fluorescence polarization, [15] resonance energy transfer, [16-18] and long-lived lanthanide emission [7, 18, 19], Chemiluminescence [20] and high-performance size-exclusion chromatography [21] have been also reported in the literature. Electrochemical assays based on immune-analysis [22], direct voltammetry in polyacrylamide hydrogels [23] and electrocatalytic reduction of $\mathrm{H}_{2} \mathrm{O}_{2}$ by myoglobin on carbon nanotube electrodes have also been reported [24]. Overall, the direct detection methods uses a labelled primary antibody to detect protein, displaying some disadvantages concerning stability, batch-to-batch (or clone-to-clone) variability, the requirement for refrigerated transport and storage and the high cost of producing antibodies

The design of synthetic biomimetic materials would therefore be an advantageous approach, and these are most commonly obtained by molecularly imprinted polymer (MIPs) technology. PIM assays have been reported to exhibit good properties in terms of selectivity, sensitivity and short response times for fast screening protein in biological simples. Moreira et al. [25] have reported various approaches to target detection of biomarkers for early PoC detection and the cardiac biomarkers such as troponin and myoglobin [25].

Even the design of Myo binding synthetic materials, also known as plastic antibodies, poses challenges [26]. Surface imprinting is a promising approach for this purpose, especially when coupled to electrochemical transduction. Several different strategies can be used to prepare such materials including: self-assembled monolayer deposition [26] ii) Thin-film polymer-formation using micro-contact imprinting [27] and iii) Designing the imprinted polymer films by grafting on a silicon surface [28]. In this work we describe the imprinting process of Myo on a graphite surface and its inclusion in PVC membranes. These membranes are permselective and allow charged proteins to diffuse through the membrane. The biorecognition element (PIM) was entrapped in the polymeric matrix and deposited on the transducer part of the sensor. In order to obtain the biosensor response, the analyte must penetrate through the membrane to PIM materials. The mass transport trough the membrane is mainly driven by the concentration gradients of species then, diffusive process is dominant [29].

Graphitic materials exhibit good structural, electronic, mechanical, optical, thermal, and chemical properties. The combination of high precision and speed, low cost of analysis, enhanced selectivity and sensitivity over a wide range of concentrations of the ion selective PVC membranes holds great promise for potential applications in biosensors [30]. Besides, measurement of membrane potential does not require the template to be extracted from the membrane, and ionic species do not have to diffuse through the membrane thus overcoming any size restrictions on the template compound [31].

For this purpose, the artificial antibody was produced by attaching Myo to oxidized surface and growing a reticulated polymer around it, by radical polymerization of 4styrenesulfonic acid (SSA) and 2-aminoethyl methacrylate hydrochloride (AEHM), used as monomers, and ethylene glycol dimethacrylate (EDGMA) employed as crosslinker. The obtained particles, PIM, were used as electroactive materials on the PVC-Myo selective membranes. These membranes were prepared by dispersing the particles in onitrophenyloctyl ether (oNPOE), acting as plasticizer, and PVC and drop coated on carbon screen printed electrodes (SPE). The resulting biomimetic sensor was evaluated by electrochemical and surface characterization techniques and applied to the analysis of myoglobin in a biofluid such as urine.

\section{Experimental}

Apparatus

The electrochemical measurements were performed using a Autolab, PGSTAT302N potentiostat (Metrohm). The equipment had an integrated Frequency Response Analyzer (FRA) module and was controlled by NOVA 7.0 software. DRPC220ATAu-SPEs were procured from DROPSENS. Working and counter electrodes were made of carbon and the pseudoreference electrode and electrical contacts made of silver. The diameter of the working electrode was $4 \mathrm{~mm}$. For electrochemical assays the SPEs were placed in a switch box (DROPSENS) to connect the electrical contacts of the AuSPE with the electrical connections of the potentiostat.

\section{Reagents}

De-ionized (conductivity $<0.1 \mu \mathrm{S} \cdot \mathrm{cm}^{-1}$ ) or ultrapure water was employed throughout this work and all chemicals were of analytical grade. Potassium hexacyanoferrate III, potassium hexacyanoferrate II trihydrate and sodium hydrogen phosphate dihydrate were obtained from Riedel-deHaen; 
potassium dihydrogen phosphate from Panreac (http://www. panreac.es/); (4-(2-hydroxyethyl)-1-piperazineethanesulfonic acid) (HEPES), from Sigma (http://www.sigmaaldrich.com/ sigma-aldrich/home.html); 4-styrenesulfonic acid sodium salt (SSA) from Alfa Aesar (http://www.alfa.com/pt/gh100w. pgm), 2-Aminoethyl methacrylate hydrochloride from Aldrich (http://www.sigmaaldrich.com/sigma-aldrich/home. html); ethylene glycol dimethacrylate (EDGMA) and sodium docedyl sulfate (SDS), sodium chloride, ethanol $99.5 \%$, Myo, $N$-hyd rox ysucc in imi de (NHS), $N$-ethy $1-N^{\prime}-(3-$ dimethylaminopropyl) carbodiimide hydrochloride (EDAC), hemoglobin $(\mathrm{Hb})$, bovine serum albumin (BSA), creatinine (Crea), sodium dodecylsulfate (SDS), o-nitrophenyloctyl ether (oNPOE) and poly(vinyl chloride) high molecular weight (PVC) from Fluka (http://www.sigmaaldrich.com/ sigma-aldrich/home.html); styrene and glacial acetic acid from Carlo Erba (http://www.carloerbareagents.com/default. aspx); and benzoyl peroxide (BPO) from Himedia (http:// www.himedialabs.com/).

Design of the plastic antibody on a graphite surface

\section{Oxidation of graphite}

Briefly, graphite powder was put placed in a solution of concentrated nitric acid and sulfuric acid (1:2 in volume) at a temperature of $80{ }^{\circ} \mathrm{C}$. When the color of the liquid was transparent, the mixture was cooled down to room temperature and diluted with deionized water and left overnight. The pretreated graphite was then immersed in an ice bath, and potassium permanganate was added carefully. When the temperature stabilized, the vessel was placed into a water bath at a temperature of $38{ }^{\circ} \mathrm{C}$ and the mixture was stirred and left for $2 \mathrm{~h}$. The vessel was then placed into an ice bath and deionized water was added drop wise to dilute the 10 times solution. Next, a solution of $30 \%$ of $\mathrm{H}_{2} \mathrm{O}_{2}$ was added to this, leading to a color changed into brilliant yellow along with bubbling. The mixture was left overnight, to absorb the upper liquid and then filtered with $\mathrm{HCl}$ aqueous solution to eliminate residual metal ions, and finally washed with water.

\section{Synthesis of biomimetic polymers}

The carboxylic acid groups in the modified graphite were activated by mixing the material in EDAC $(50 \mathrm{mmol}$. $\left.\mathrm{L}^{-1}\right)$ and NHS $\left(25 \mathrm{mmol} \cdot \mathrm{L}^{-1}\right)$. The particles were then washed with ultrapure water and incubated in $1 \times$ $10^{-4} \mathrm{~mol} \cdot \mathrm{L}^{-1}$ Myo prepared in phosphate buffered saline (PBS) solution, $\mathrm{pH} 7.0$, for $2.5 \mathrm{~h}$, at $4{ }^{\circ} \mathrm{C}$. Then, the material was thoroughly washed with PBS buffer and subsequently ultrapure water to remove any weakly adsorbed Myo (Fig. 1b).
Polymerization in the presence of Myo was carried out by adding $1 \mathrm{~mL}$ of $5.0 \times 10^{-4} \mathrm{~mol} \cdot \mathrm{L}^{-1} \mathrm{SSA}$ and $5.0 \times 10^{-4} \mathrm{~mol}$. $\mathrm{L}^{-1}$ of AEHM, $5.0 \times 10^{-4} \mathrm{~mol} \cdot \mathrm{L}^{-1} \mathrm{BPO}$ and EDGMA $1.0 \times$ $10^{-2} \mathrm{~mol} \cdot \mathrm{L}^{-1}$ solution (Fig. $1 \mathrm{c}$ and d). The polymerization was carried out at $38{ }^{\circ} \mathrm{C}$, for $3 \mathrm{~h}$ (Fig. 1d). The material so obtained was thoroughly washed with deionized water and incubated in a solution of diluted acetic acid $10 \%$ and SDS $10 \%$ for $2 \mathrm{~h}$ (Fig. 1e). The imprinted sensor was washed and conditioned in PBS buffer, $\mathrm{pH} 7.4$ during $1 \mathrm{~h}$. Then the sensor was washed several times with ultrapure water.

Preparation of the selectivemembranes

The Myo-selective membranes were prepared by mixing $71 \mathrm{mg}$ of PVC, $120 \mathrm{mg}$ of plasticizer $o$-nitrophenyloctyl ether (oNPOE) and $2.5 \mathrm{mg}$ of polymer, (either PIM or CM). The mixture was stirred until the PVC was well moistened, and then dispersed in $1.0 \mathrm{~mL}$ THF. These membranes were cast over the carbon layer on the working electrode area of the SPE. Membranes were left dry for $24 \mathrm{~h}$ and conditioned in a $1 \times 10^{-5} \mathrm{~mol} \cdot \mathrm{L}^{-1}$ Myo solution.

Electrochemical assays

Square wave voltammetry (SWV) measurements were conducted in a mixture of $5.0 \mathrm{mmol} \cdot \mathrm{L}^{-1}$ of $[\mathrm{Fe}(\mathrm{CN}) 6]^{3-/ 4-}$ prepared in MES buffer, $\mathrm{pH}$ 5.0. In these, the potential was scanned from -0.7 to $+0.7 \mathrm{~V}$, at $30 \mathrm{mV} . \mathrm{s}^{-1}$. In SWV studies potentials were changed from -0.7 to $+0.7 \mathrm{~V}$, at a $0.125 \mathrm{~V} . \mathrm{s}^{-1}$, corresponding to a frequency of $20 \mathrm{~Hz}$ and step height of $150 \mathrm{mV}$.

Surface analysis

\section{Fourier transform infrared spectroscopyanalysis}

The Fourier transforminfrared spectroscopy (FTIR) spectra of graphite, graphite oxide and PIM particles were measured in a Nicolet 6700 FTIR spectrometer, coupled to a diamond ATR (attenuated total reflectance) prism. The spectra were collected under temperature and humidity control immediately after background correction. The number of scans was 32 for both sample and background.

\section{Raman spectral analysis}

Raman microscopy was carried out using a Labram 300 Jobin Yvon spectrometer, equipped with laser operating at $532 \mathrm{~nm}$ and with a power of $50 \mathrm{~mW}$. Spectra were recorded as an extended scan. The laser beam was focused either with a $50 \times$ or a $100 \times$ Olympus objective lens. The laser power at the surface of the samples was varied using a set of neutral density filters (optical densities 0.3, 0.6, 1 and 2). 
Fig. 1 The different stages of the molecular-imprinting polymer synthesis

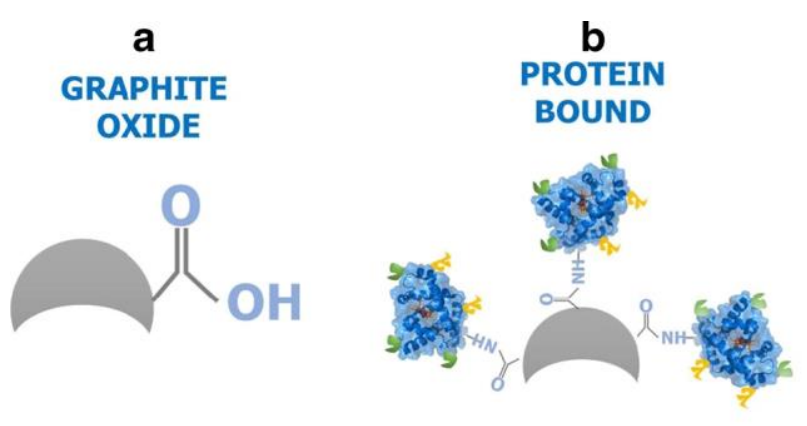

b

PROTEIN

e

TEMPLATE REMOVAL

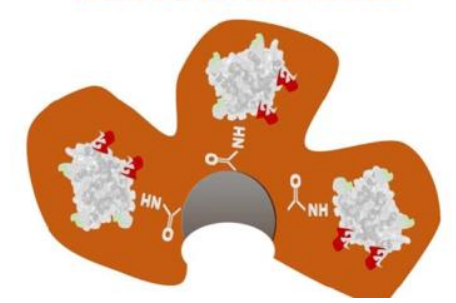

C

CHARGE

LABELLING

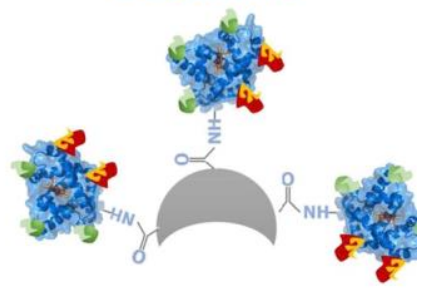

d

POLYMERIZATION

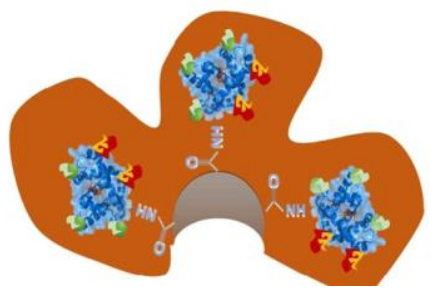

Scanning electron microscope and energy dispersive spectrometeranalysis

Scanning electron microscope (SEM) analysis was carried in a high resolution field emission gun scanning electron microscope (LEO Gemini 1525 FEGSEM, Oxford Instruments, UK). SEM images were collected of the dried PIM, PIM with template present, $\mathrm{CM}$ and graphitic materials, at room temperature and in low vacuum mode. The samples were metallized with chromium using a SEM sputtering system. Energy Dispersive Spectrometer (EDS) analysis was carried out in several points of each sample.

\section{Selectivity}

The interfering species tested were $\mathrm{Hb}, \mathrm{BSA}, \mathrm{Crea}$ and $\mathrm{NaCl}$, prepared in MES buffer $\mathrm{pH} 4.5$ in the concentration range $1.08-14.40 \mu \mathrm{g} \cdot \mathrm{mL}^{-1}$. The measurements were performed by SWV.

\section{Urine samples analysis}

The performance of the plastic antibody was studied using urine samples spiked with Myo in the range 1.08-21.60 $\mu \mathrm{g}$. $\mathrm{mL}^{-1}$. The urine was 1:10 diluted in MES buffer $\mathrm{pH} 4.5$. The concentration of Myo studied was the same as the calibration curves $\left(1.08-28.8 \mu \mathrm{g} \cdot \mathrm{mL}^{-1}\right)$.

\section{Design of the biosensor}

Several authors have been promoting the elegance of natural antibodies and trying to mimic it. One greatest advantage of the artificial antibodies is the capability to create and innovate the respective molecular design. Characteristics such as stability, flexibility and permeability can be modulated according to the need. For the plastic antibodies' design several factors need to be considered such as easy preparation and low cost, stability and activity under wide operation conditions, selective and strong binding and guest binding in water.

In this work a novel molecular imprinted polymer on a graphite surface was developed for Myo detection in point of care. The first step of the tailoring process was the graphite oxidation with $\mathrm{H}_{2} \mathrm{SO}_{4} / \mathrm{HNO}_{3}$ mixture and subsequent activation of the carboxylic acids with EDAC and NHS (Fig. 1a). These reagents catalyze the reaction between carboxylic and amine groups to form amide crosslinks. EDAC first activates a carboxylic group, which then reacts with NHS to produce an activate ester that undergoes nucleophilic substitution by amine groups on the protein. This means that the protein was covalently attached under physiological conditions (PBS buffer $\mathrm{pH}$ 7.4) supporting the integrity in terms of conformation and structure (Fig. 1b).

The imprinting approach involved self-assembly of the monomer units around the Myo (Fig. 1c) followed by a radical polymerization with the addition of an initiator and finally (Fig. 1d) template removal in acidic medium (Fig. 1e).

The monomeric arrangement was based on the effect of electrostatic charge density on the recognition of the Myo host to tailor the polymer, using AEMH as a positively charged monomer and SSA as a negatively charged monomer (Fig. 1c). The SSA monomer was effectively introduced as a strong negatively charged ion $\left(-\mathrm{SO}_{3}^{-}\right)$in the polymerization step, enhancing the proton conductivity from the sulfonic acid group involved in the SSA on the plastic antibody surface 
[32]. The simultaneous presence of two oppositely charged monomers in the pre-polymerization mixture resulted in imprinted with cavities that contain complementary and specific functional group orientation.

The time and monomer/cross-linker concentrations used in this stage were of particular importance because if the polymer layer is too thick it may entrap the protein irreversibly. The polymerization time was fewer than $3 \mathrm{~h}$ avoiding changes in the conformation of the protein. The temperature at which this polymerization reaction took place was also important because the imprinted conformation should match that of Myo in the samples, in this work the temperature was $38^{\circ} \mathrm{C}$ near to the physiological conditions (Fig. 1d). Finally, the proteolysis of the attached protein was carried out by reaction with Acetic acid /SDS to empty the imprinted sites (Fig. 1e). Subsequently, several washing steps were performed to remove the released peptide fractions and enzyme from the sensory surface. Non-imprinted polymers were submitted to the same treatment to avoid any differences in comparing to the imprinted polymers.

\section{Results and discussion}

Surface analysis of the host-tailored polymers

\section{Raman spectroscopicanalysis}

Raman spectroscopy is a widely used tool for the characterization of graphite and carbon nanotubes, especially considering the fact that conjugated and carbon-carbon double bonds lead to high Raman intensities.

Raman spectroscopy is used to identify carbon materials and for their characterization after chemical modification [33]. In Fig. 2 we present Raman spectra of Graphite (G), Graphite Oxide (GO), PIM/Myo and CM. In all samples, two prominent peaks are clearly visible, corresponding to the so-called $\mathrm{G}$ peak, which corresponds to the Brillouin-zone-centered LOphonon around $1590 \mathrm{~cm}^{-1}$, and D peak, which corresponds to the double-resonance excitation of phonons close to the $\mathrm{K}$ point in the Brillouin zone around $1330 \mathrm{~cm}^{-1}$ [33]. The Raman spectra shows a notable fact, the $G$ band peak is located at a higher frequency in GO than that in graphite $\left(1603.3 \mathrm{vs} 1578.5 \mathrm{~cm}^{-1}\right)$. This is a consequence of the extensive chemical modification on graphite surface in the oxidation process.

The intensity ratio (ID/IG) is characteristic of the extent of disorder present within in the material [33]. The ID/IG ratios of the G, GO, PIM/Myo, CM are respectively 0.65, 0.99, 1.10 , 1.05 and reflecting the increase in disorder and the occurrence of the polymerization on the GO surface. Furthermore, there is only a little increase in intensity ratio for graphite imprinting and CM. By comparing the G-bands of GO and PIM/Myo, it is clear that G-band of GO- PIM occurs at $1595.4 \mathrm{~cm}^{-1}$, which is downshifted by $8 \mathrm{~cm}^{-1}$ compared to that of GO. The Raman shifts of the G band for PIM/Myo, provide evidence for the charge transfer between the GO and PIM, which suggests a strong interaction between the PIM and the GO sensor. Another peak is present at 2665.7 and $2910 \mathrm{~cm}^{-1}$ in all sensors except in graphite. The differences in the intensity ratio demonstrated the occurrence of chemical reaction between the $\mathrm{GO}$ and the monomers suggesting the occurrence of the polymerization.

\section{Fourier Transform Infrared Spectroscopy analysis}

Structural changes in graphite were confirmed by FTIR spectra. The Fig. 3 presents FTIR spectra of Graphite (G), Graphite Oxide (GO) and PIM/Myo.

The bands at 2917 and $2850 \mathrm{~cm}^{-1}$ in the PIM material are assigned to the presence of the $\mathrm{C}-\mathrm{H}$ stretch in the $\mathrm{sp}^{3}$ hybridized carbons. It is probable that the peak at $2950 \mathrm{~cm}^{-1}$ assigned the presence of unsaturated carbon material ( $\mathrm{sp}^{2}$ hybridized carbon) within the PIM polymeric structure.
Fig. 2 Raman analysis of PIM, $\mathrm{CM}$ graphite oxide and graphite

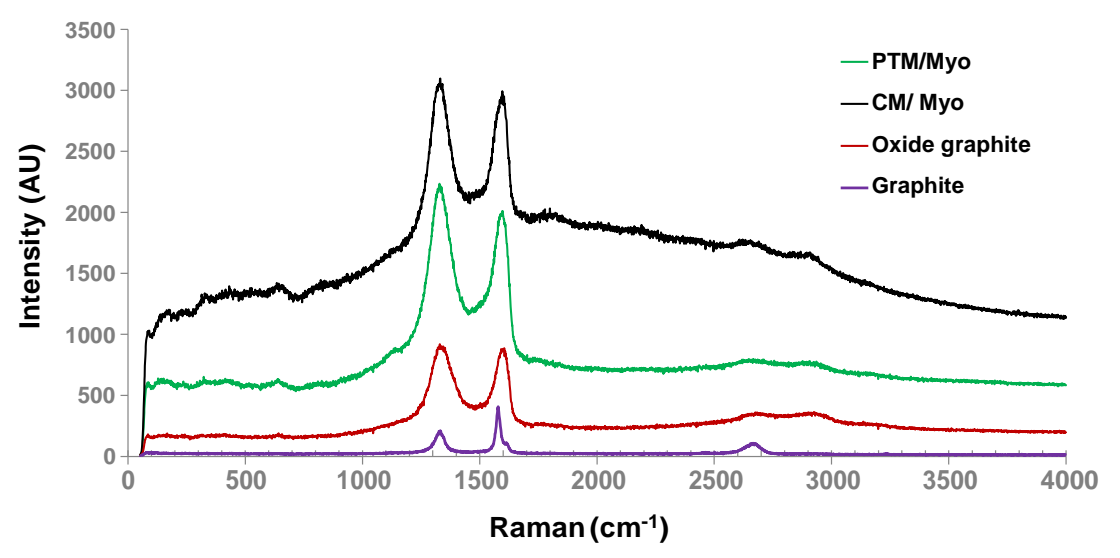


Fig. 3 FTIR spectra of graphite, oxidized graphite and PIM

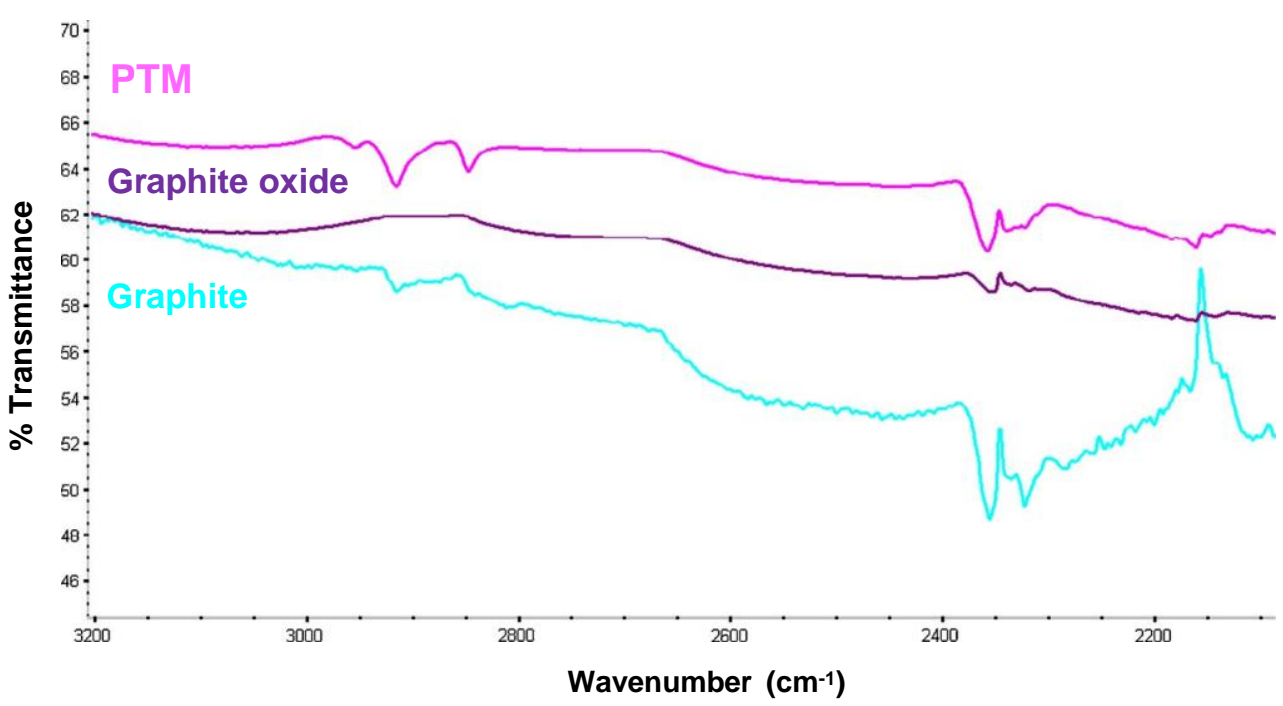

Scanning electron microscope and energy dispersive spectrometeranalysis

The occurrence of imprinting could not be proven by means of SEM, because the PIM and CM materials were similar. However, the chemical modification and imprinting effect of the surface was easily detected by EDC analysis. The chemical modification of the graphite introduced $\mathrm{C}$ and $\mathrm{O}$ in the overall structure (EDS spectra in Fig. 4). This was present in both PIM/Myo, PIM/Myo without template removal and CM biomaterials. PIM without template removal structures displayed, however, higher levels of these atoms, which probably resulted from prevailing protein structures sequestered inside the imprinted layer.

\section{Analytical performance of the sensors}

\section{Square wave voltammetry measurements}

Electrochemical assay provides analytical techniques characterized by instrumental simplicity, low cost and portability. This technique is sensitive, selective, rapid and readily applicable to analysis in most areas of analytical chemistry.

Square wave voltammetry (SWV) displayed several advantages such as high effective scan rate thus reducing the scan time, increased analytical sensitivity and relative insensitivity to the presence of dissolved oxygen [34]. Another advantage of SWV is the difference current is larger than either forward or reverse currents, meaning that the height of the peak is usually relatively easy to read, consequently increasing the accuracy.

To evaluate de interaction between PIM and CM sensor and the (Myo), the sensor surface was in contact with different concentrations of Myo. SWV measurents were performed in
MES buffer $(\mathrm{pH} 4.5)$ in $5.0 \mathrm{mmol} \cdot \mathrm{L}^{-1}[\mathrm{Fe}(\mathrm{CN}) 6]^{3-}$ and $5.0 \mathrm{mmol} \cdot \mathrm{L}^{-1}\left[\mathrm{Fe}(\mathrm{CN})_{6}\right]^{4-}$. The $\mathrm{SWV}$ readings were carry out by the amplitude $0.15 \mathrm{~V}$.

In SWV assays, Myo binding was shown by a decrease in the typical anodic peak current of redox probe solutions (Fig. 4). Higher Myo concentrations yielded smaller peaks. A linear pattern against Log[Myo] was observed for concentrations down to $1.08 \mu \mathrm{g} \cdot \mathrm{mL}^{-1}$ (Fig. 4) and with slope $-0.1735 \pm 0.784 \mu \mathrm{A}$ decade $^{-1}$ (see Figs. 4 and 5) and maximum overall peak at $0.437 \mathrm{~V}$.

CM polymer displayed linear behavior after $7.2 \mu \mathrm{g} \cdot \mathrm{mL}^{-1}$ and the maximum overall peak were situated in a different potential value $0.532 \mathrm{~V}$. These results indicated that the PIM/ Myo showed better general performance compared with the CM sensor.

\section{Selectivity study}

The selectivity study is crucial for sensor performance evaluation. The interfering species tested were selected among those that may be found in biological fluids, such as $\mathrm{Hb}$, BSA, Crea and $\mathrm{NaCl}$ in concentration range within 1.08$14.40 \mu \mathrm{g} \cdot \mathrm{mL}^{-1}$. Each assay was conducted in a different PIM/Myo sensor, in order to avoid a cross contamination from previously adsorbed Myo or interfering compounds. It is important to highlight that the peaks currents observed belonged to the iron redox probe (present in the solution) and not to any other electrochemical active species at this region. So, the interfering study measured the effect of the interfering species upon this redox peak (shift and peak height).

As may be seen in Fig. 6, all species caused a right shift of the peak potential of the Myo reading. Significant interference could be observed at the maximum peak current of Myo assay, but if analytical readings are made at $0.24 \mathrm{~V}$, these interfering 


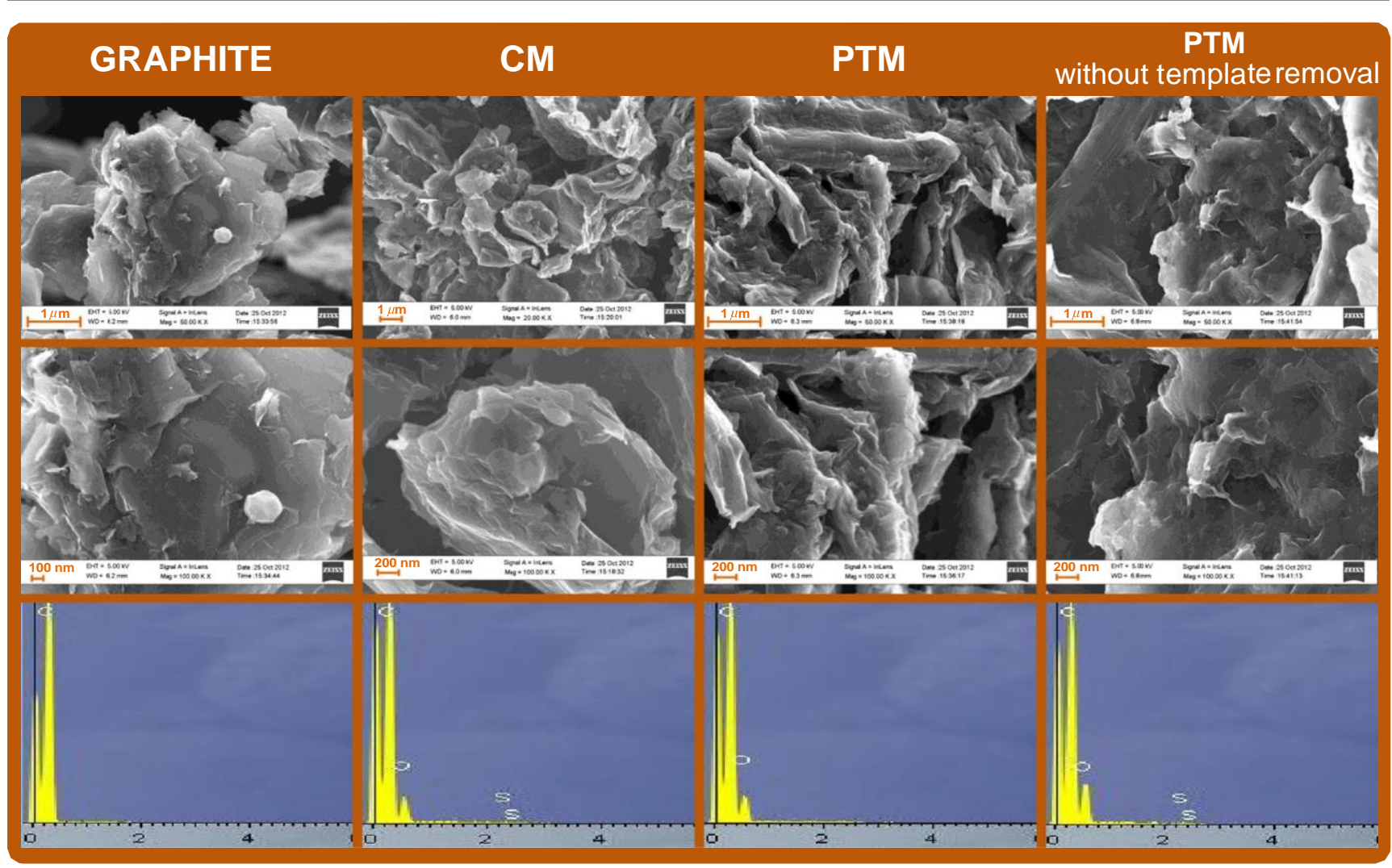

Fig. 4 SEM and EDC images of graphite, CM, PIM with protein and PIM

effects become negligible. The overall peak for Myo, $\mathrm{Hb}$, Crea and BSA were respectively 0.437, 0.523, 0.296 and $0.559 \mathrm{~V}$. We can conclude that the PIM/Myo displayed good features in terms of selectivity, due its different peak potential.

a

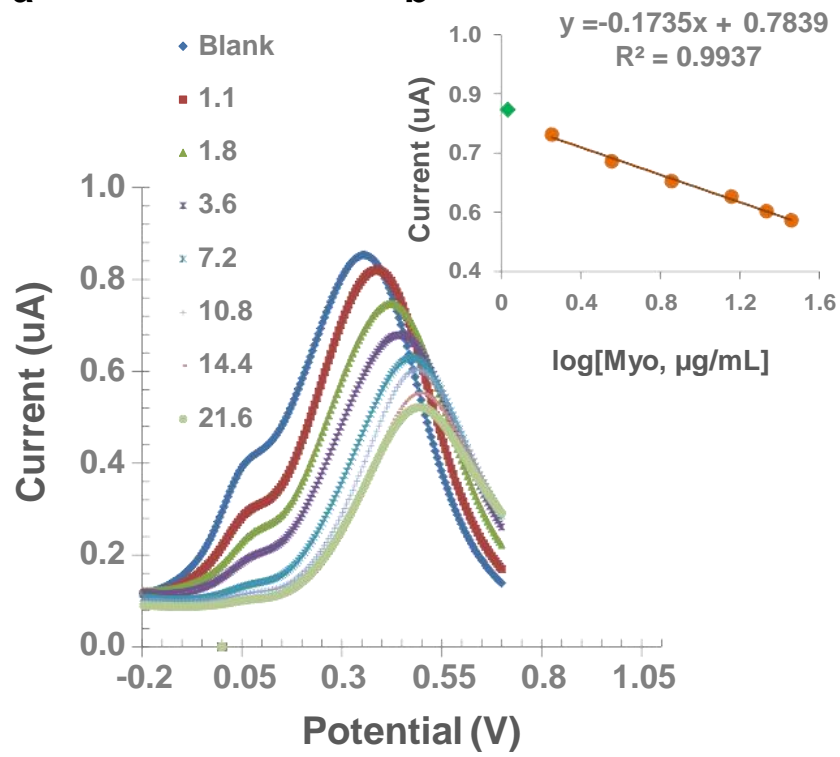

Fig. 5 SWVa of PIM material and the corresponding calibration curve b in $5.0 \mathrm{mM}[\mathrm{Fe}(\mathrm{CN}) 6]^{3-}$ and $5.0 \mathrm{mM}[\mathrm{Fe}(\mathrm{CN}) 6]^{4-}$, in MES buffer pH 4.5, with different concentrations of Myo
Myoglobin assay

The standard addition method was applied to determine Myo in spiked urine samples, ranging from $1.08-21.60 \mu \mathrm{g} \cdot \mathrm{mL}^{-1}$

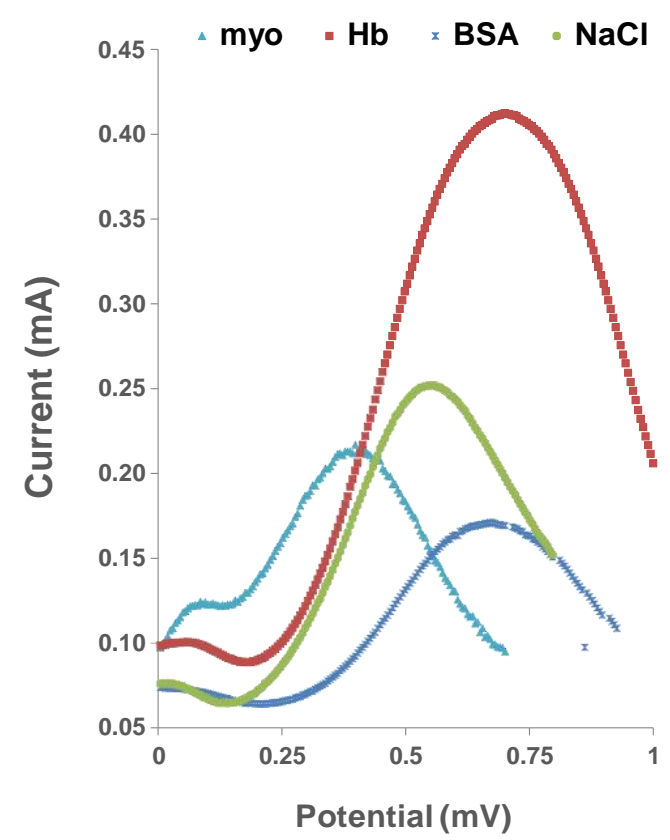

Fig. 6 SWV spectra of the different interfering species Myo, Hb, BSA and $\mathrm{d} \mathrm{NaCl}$ with $3.6 \mu \mathrm{g} \cdot \mathrm{mL}^{-1}$, respectively 
Table 1 Figures of merit of comparable methods for determination of cardiac biomarker proteins

\begin{tabular}{|c|c|c|c|c|c|}
\hline Transduction platform & $\begin{array}{l}\text { Detection } \\
\text { range } \\
\left(\mathrm{ng} \cdot \mathrm{mL}^{-1}\right)\end{array}$ & $\begin{array}{l}\text { Bioreco-gnition } \\
\text { element }\end{array}$ & Comments & Year & Ref. \\
\hline Fluorescence & 31.0 & Antibody & $\mathrm{pH} 7.2$ High price (antibody) Needs storage at $4{ }^{\circ} \mathrm{C}$ & 2014 & [1] \\
\hline Fluorescence & 10.0 & Antibody & $\begin{array}{l}\mathrm{pH} 7.2 \text { High price (antibody) High price } \\
\text { (indium-tin-oxide-coated glass) Needs storage at } 4{ }^{\circ} \mathrm{C}\end{array}$ & 2014 & [3] \\
\hline Fluorescence & 2.0 & Antibody & $\begin{array}{l}\mathrm{pH} 7.2 \text { High price (antibody) Low price (paper) } \\
\text { Need storage at } 4{ }^{\circ} \mathrm{C}\end{array}$ & 2014 & [4] \\
\hline $\begin{array}{l}\text { Faradaic, nanoparticles } \\
\text { modified electrodes }\end{array}$ & 17.8 & Antibody & $\begin{array}{l}\mathrm{pH} 7.2 \text { High price (antibody) High price } \\
\text { (gold nanoparticles) Need storage at } 4{ }^{\circ} \mathrm{C}\end{array}$ & 2010 & [5] \\
\hline Faradaic, & 5.0 & Antibody & $\begin{array}{l}\mathrm{pH} 7.2 \text { High price (antibody) Low price (nanoparticles } \\
\text { modified Fe grafite eletrodes) Need storage at } 4{ }^{\circ} \mathrm{C}\end{array}$ & 2011 & [6] \\
\hline $\begin{array}{l}\text { Polyaniline nanowires/ } \\
\text { conductance }\end{array}$ & 1.4 & Aptamer & $\mathrm{pH}$ 7.4 High price (antibody) Need storage at $4{ }^{\circ} \mathrm{C}$ & 2010 & [7] \\
\hline Electrochemical SPAM & 580.0 & Molecular imprinting & $\begin{array}{l}\text { pH } 5 \text { Low price (plastic antibody) Low price } \\
\text { (plastic antibody) Low price (gold/SPE) } \\
\text { Storage at room temperature }\end{array}$ & 2013 & {$[8]$} \\
\hline Electrochemical Potentiometry & 217.0 & Molecularimprinting & $\begin{array}{l}\mathrm{pH} 4 \text { Low price (plastic antibody) Low price } \\
\text { (graphite electrodes) Storage at room temperature }\end{array}$ & 2011 & [9] \\
\hline Electrochemical & 225.0 & Molecular imprinting & $\begin{array}{l}\mathrm{pH} 5 \text { Low price (plastic antibody) Low price } \\
\text { (gold/SPE) Storage at room temperature }\end{array}$ & 2013 & {$[10]$} \\
\hline Electrochemical & 79.0 & Molecularimprinting & $\begin{array}{l}\mathrm{pH} 5 \text { Low price (plastic antibody) Low price } \\
\text { (gold/SPE) Storage at room temperature }\end{array}$ & - & Present work \\
\hline
\end{tabular}

Myo. The linear behavior was obtained in the range studied with slope $-0.464 \pm 0.05 \mu \mathrm{A}$ decade $^{-1}$ and LLLR $1.08 \mu \mathrm{g}$. $\mathrm{mL}^{-1},(Y=-0.45 \mathrm{X}+0.989)$, according to the calibration curve. These results pointed out the accuracy and the precision of the analytical data, suggesting that it may turn out a successful approach for screening AMI episodes in POC.

A good agreement was found between added and found amounts of Myo. Results of the electrochemical analysis conducted in steady state showed recoveries ranging 102.0$110.2 \%$ with an average relative standard deviation of $1.8 \%$.

\section{Conclusions}

Surface imprinting of Myo tailored on graphite surface was successfully established by merging self-assembled monolayer and molecular imprinting technologies. There are several advantages out coming from this approach, including that there are no requirements of the covalent linkage of the analyte (at the imprinting stage) or/and biorecognition element (in the substrate surface), and the permselectivity characteristics of the plasticized membranes may enhance the selectivity performance.

An extensive comparison of the described method may be found in Table 1. In general, devices using imprinted materials are less expensive and much more stable (thermally and chemically) than immunoassays. Compared to previous devices, the present work offers a greater simplicity at the device construction, because new electrodes may be prepared in $\sim 1 \mathrm{~h}$, after casting a membrane that has already been prepared (and stable at $4{ }^{\circ} \mathrm{C}$ for a minimum of 1 month).

SWV transduction offer suitable selectivity features for practical application and quick responses. Overall, these methods relying on imprinted PVC/PIM/Myo membranes applied on SPE device is simple, of low cost, precise, accurate and inexpensive, and may turn out an alternative method for screening Myo in POC.

Acknowledgments One of the authors (FTCM) gratefully acknowledges Fundação para a Ciência e Technologia for the financial support (PhD grant referenceSFRH/BD/66735/2009).

\section{References}

1. Braunwald E, Antman EM, Beasley JW, Califf RM, Cheitlin MD, Hochman JS et al (2000) ACC/AHA guidelines for the management of patients with unstable angina and non-ST segment elevation myocardial infarction: executive summary and recommendations. Catheter Cardiovasc Interv 51:505-521

2. Braunwald E, Antman EM, Beasley JW, Califf RM, Cheitlin MD, Hochman JS et al (2000) ACC/AHA guidelines for the management of patients with unstable angina and non-ST-segment elevation myocardial infarction. J Am Coll Cardiol 36:970-1056

3. Hing E, Hall MJ, Ashman JJ, Xu J (2010) National hospital ambulatory medical care survey: 2007 outpatient department summary. Nat Health Stat Rep 28:1-32

4. Butler KH, Swencki SA (2006) Chest pain: a clinical assessment. Radiol Clin N Am 44:165-179

5. Balk EM, Ioannidis JPA, Salem D, Chew PW, Lau J (2001) Accuracy of biomarkers to diagnose acute cardiac ischemia in the emergency department: a meta-analysis. Ann Emerg Med 37:478-494 
6. Nursalim A, Suryaatmadja M, Panggabean M (2013) Potential clinical application of novel cardiac biomarkers for acute myocardial infarction. Acta Med Indones-Indones J Intern Med 45:240-250

7. Matveeva EG, Gryczynski Z, Lakowicz JR (2005) Myoglobin immunoassay based on metal particle-enhanced fluorescence. J Immunol Methods 302:26-35

8. Castaldo AM, Ercolini P, Forino F, Basevi A, Vrenna L, Castaldo P et al (1994) Plasma myoglobin in the early diagnosis of acute myocardial-infarction. Eur J Clin Chem Clin Biochem 32:349-353

9. Kent L, Ahchean C, Januzzi J (2002) Cardiac markers for myocardial infarction. Am J Clin Pathol 118:S93-S99

10. Beuerle JR, Azzazy HME, Apple FS et al (2000) Performance characteristics of a new myoglobin microparticle enzyme immunoassay: a multicenter evaluation. Clin Biochem 33:595-598

11. Graff LG, Dallara J, Ross MA, Joseph AJ, Itzcovitz J, Andelman RP et al (1997) Impact on the care of the emergency department chest pain patient from the chest pain evaluation registry (CHEPER) study. Am J Cardiol 80:563-568

12. Gosling JP (1990) A decade of development in immunoassay methodology. Clin Chem 36:1408-1427

13. Jameson DM, Croney JC (2003) Fluorescence polarization: past, present and future. Comb Chem High Throughput Screen 6:167-176

14. Luppa PB, Sokoll LJ, Chan DW (2001) Immunosensors - principles and applications to clinical chemistry. Clin Chim Acta 314:1-26

15. Mishra SK, Srivastava AK, Kumar D (2014) Bio-functionalized Pt nanoparticles based electrochemical impedance immunosensor for human cardiac myoglobin. Rsc Adv 4:21267-21276

16. Dürkop A, Lehmann F, Wolfbeis OS (2002) Polarization immunoassays using reactive ruthenium metal-ligand complexes as luminescent labels. Anal Bioanal Chem 372:688-694

17. Hayes MA, Petkus MM, Garcia AA et al (2009) Demonstration of sandwich and competitive modulated supraparticle fluoroimmunoassay applied to cardiac protein biomarker myoglobin. Analyst 3:533-541

18. Cho J-H, Kim M-H, Mok R-S (2014) Two-dimensional paper chromatography-based fluorescent immunosensor for detecting acute myocardial infarction markers. J Chromatogr B-Anal Technol Biomed Life Sci 967:139-146

19. Kim D-H, Seo S-M, Cho H-M, Hong S-J, Lim D-S, Paek S-H (2014) Continuous immunosensing of myoglobin in human serum as potential companion diagnostics technique. Biosens Bioelectron 62:234-241

20. Hashimoto M, Tsukagoshi K, Nakajima R, Kondo K (1999) Chemiluminescence detection of heme proteins separated by capillary isoelectric focusing. J Chromatogr A 852:597-601

21. Liang HR, Scott MK, Murry DJ, Sowinski SM (2001) Determination of albumin and myoglobin in dialysate and ultrafiltrate samples by high-performance size-exclusion chromatography. J Chromatogr B 754:141-151

22. Shen L, Huang R, Hu NF (2002) Myoglobin in polyacrylamide hydrogel films: direct electrochemistry and electrochemical catalysis. Talanta 56:1131-1139

23. Shumiantseva VV, Bulko TV, Vagin MI, Suprun EV, Archakov AI (2010) Electrochemical immunoanalysis of cardiac myoglobin. Biomed Khim 56:758-768

24. Suprun EV, Shilovskaya AL, Lisitsa AV, Bulko TV, Shumyantseva VV, Archakov AI (2011) Electrochemical immunosensor based on metal nanoparticles for cardiac myoglobin detection in human blood plasma. Electroanalysis 23:1051-1057

25. Moreira FTC, Sharma S, Dutra RAF, Noronha JPC, Cass AEG, Sales MGF (2013) Smart plastic antibody material (SPAM) tailored on disposable screen printed electrodes for protein recognition: application to myoglobin detection. Biosens Bioelectron 45: 237-244

26. Wulff G (2013) Fourty years of molecular imprinting in synthetic polymers: origin, features and perspectives. Microchim Acta 15-16: $1359-1370$

27. Moreira FTC, Dutra RAF, Noronha JPC, Sales MGF (2011) Myoglobin-biomimetic electroactive materials made by surface molecular imprinting on silica beads and their use as ionophores in polymeric membranes for potentiometric transduction. Biosens Bioelectron 26:4760-4766

28. Moreira FTC, Dutra RAF, Noronha JPC, Sales MGF (2013) Electrochemical biosensor based on biomimetic material for myoglobin detection. Electrochim Acta 107:481-487

29. Pijanowska DG, Torbicz W (2008) Ion selective and semi-permeable membranes for biosensors in biomedical applications. Biocybernetics Biomed Eng 28:11-19

30. Piletsky SA, Turner APF (2002) Electrochemical sensors based on molecularly imprinted polymers. Electroanalysis 14:317-323

31. Guerreiro JRL, Sales MGF, Moreira FTC, Rebelo TSR (2011) Selective recognition in potentiometric transduction of amoxicillin by molecularly imprinted materials. Eur Food Res Technol 232:3950

32. Hong L, Chen NP (2000) Proton-conducting polymer membrane based on sulfonated polystyrene microspheres and an amphiphilic polymer blend. J Pol Sci Part B-Pol Phys 38:1530-1538

33. Kudin KN, Ozbas B, Schniepp HC, Prud'homme RK, Aksay IA, Car R (2008) Raman spectra of graphite oxide and functionalized graphene sheets. Nano Lett 8:36-41

34. Miles AB, Compton RG (2000) The theory of square wave voltammetry at uniformly accessible hydrodynamic electrodes. J Electroanal Chem 487:75-89 